\title{
Efeito materno na expressão dos teores de aminoácidos sulfurados em grãos de feijão
}

\author{
Maternal effect in sulfur amino acids content expression in common bean grains
}

\author{
Patrícia Medianeira Grigoletto Londero ${ }^{\mathrm{I}}$ Nerinéia Dalfollo Ribeiro ${ }^{\mathrm{II}}$ Taiguer Cerutti ${ }^{\mathrm{III}}$ \\ Sandra Maria Maziero ${ }^{\mathrm{III}}$ Daniele Piano Rosa ${ }^{\mathrm{III}}$ Simone Saydelles da Rosa ${ }^{\mathrm{I}}$
}

\begin{abstract}
A genética do teor de aminoácidos sulfurados em feijão não tem sido suficientemente avaliada, por isso o objetivo deste trabalho foi verificar se ocorre efeito materno na expressão dos teores de aminoácidos sulfurados (metionina e cisteína) em grãos de feijão. Para isso, foram realizados cruzamentos controlados entre as cultivares 'BRS Valente' $x$ 'IAPAR 44' $e$ 'TPS Nobre' $x$ 'Minuano', e as gerações $F_{1}, F_{1}$ recíproco, $F_{2} e$ $\mathrm{F}_{2}$ recíproco foram obtidas para cada combinação híbrida. Os aminoácidos sulfurados foram determinados por cromatografia líquida de alto desempenho (HPLC-UV). O teor de metionina variou de $0,79 \mathrm{~g}$ por $16 \mathrm{~g}$ de $\mathrm{N}$ da matéria seca MS ('BRS Valente') a 1,09g por $16 \mathrm{~g}$ de $N$ da MS (geração $F_{2}$ ), e o teor de cisteína variou de $0,76 \mathrm{~g}$ por $16 \mathrm{~g}$ de $\mathrm{N}$ da MS (geração $F_{2}$ ) a 1,43g por $16 \mathrm{~g}$ de $N$ da MS ('Minuano'). Variabilidade genética foi observada entre os genitores, porém não ocorre efeito materno na expressão dos teores de metionina $e$ de cisteína em feijão. A seleção para maior teor de aminoácidos sulfurados em grãos de feijão deve ser realizada em sementes $F_{2}$, pois a geração do embrião é $F_{2}$.
\end{abstract}

Palavras-chave: Phaseolus vulgaris L., variabilidade genética, gerações precoces, seleção.

\section{ABSTRACT}

The genetic of the sulfur amino acids content has not been sufficiently evaluated in common bean. The objective of this research was to investigate the existence of maternal effect in sulfur amino acids content (methionine and cystein) of common bean grains. The controlled crossings were performed among the cultivars 'BRS Valente' $x$ 'IAPAR 44' and 'TPS Nobre' $x$ 'Minuano'. The $F_{1}, F_{1}$ reciprocal, $F_{2}$ and $F_{2}$ reciprocal

\begin{abstract}
generations were obtained for each hybrid combination. The amino acid content was determined by high performance liquid chromatography (HPLC-UV). The methione content varied from $0.79 \mathrm{~g}$ for $16 \mathrm{~g} \mathrm{~N}$ MS ('BRS Valente') to $1.09 \mathrm{~g}$ for $16 \mathrm{~g}$ MS (F2 generation) and the cystein content varied from $0.76 \mathrm{~g}$ for $16 \mathrm{~g} \mathrm{~N} \mathrm{MS}$ ( $\mathrm{F}_{2}$ generation) to $1.43 \mathrm{~g}$ for $16 \mathrm{~g} \mathrm{~N} \mathrm{MS}$ ('Minuano'). Genetic variability was observed between the parents, but was there was no maternal effect in the methione and cystein content. The selection for higher sulfur amino acids content can be performed in $F_{2}$ seeds, because the generation of the embryo is $F_{2}$.
\end{abstract}

Key words: Phaseolus vulgaris L., genetic variability, early generation, selection.

Os alimentos de origem animal são fontes de proteína de valor biológico mais elevado (MOLINA et al., 2001). Porém, o consumo desses produtos pode ser restringido por razões econômicas, religiosas ou culturais. Por isso, as fontes de proteína de origem vegetal têm sido amplamente utilizadas para a alimentação humana.

A proteína do feijão (Phaseolus vulgaris L.) tem sido considerada de baixo valor biológico, pois é deficiente em aminoácidos sulfurados - metionina e cisteína - apesar de apresentar, em sua constituição, todos os aminoácidos essenciais (ANTUNES et al., 1995; MARQUES \& BORA, 2000; GUZMÁNMALDONADO et al., 2000). Por isso, a metionina e a

IPrograma de Pós-graduação em Agronomia (PPGA), Universidade Federal de Santa Maria (UFSM), Campus Universitário, 97105900, Santa Maria, RS, Brasil.

IIDepartamento de Fitotecnia, Centro de Ciências Rurais (CCR), UFSM, Campus Universitário, 97105-900, Santa Maria, RS, Brasil. E-mail: neiadr@smail.ufsm.br. Autor para correspondência.

${ }^{\text {IIIC }}$ urso de Agronomia, CCR, UFSM, Santa Maria, RS, Brasil. 
cisteína deverão ser suplementadas na alimentação, com a utilização de cereais, para que sejam obtidos teores de aminoácidos adequados para suprir as necessidades diárias do organismo humano. Entretanto, RIBEIRO et al. (2007) observaram que algumas cultivares de feijão, disponíveis para o cultivo no Brasil, apresentaram teores de aminoácidos sulfurados superiores ao padrão de $1,7 \mathrm{~g}$ por $16 \mathrm{~g}$ de $\mathrm{N}$ da matéria seca (MS), para o somatório metionina + cisteína, que é considerado adequado pela Food and Agriculture Organization (FAO) para suprir as necessidades nutricionais de um indivíduo adulto (FAO, 1998).

Os teores de metionina e de cisteína, em feijão, variam com o grupo comercial, com a cultivar e com o ambiente de cultivo (ANTUNES et al., 1995; MARQUES \& BORA, 2000; GUZMÁNMALDONADO et al., 2000; RIBEIRO et al., 2007). Além disso, herdabilidade moderada em sentido restrito foi obtida para o teor de metionina (KELLY \& BLISS, 1975), indicando que ganhos com a seleção poderão ser obtidos.

O controle genético do teor de metionina e de cisteína foi pouco estudado, e há dúvidas se esses caracteres são dependentes do tegumento que é tecido materno e/ou dos cotilédones que são produtos da fecundação. Efeito materno foi observado na expressão do teor de proteína (LELEJI et al., 1972), do tempo de cozimento (RIBEIRO et al., 2006) e dos teores de cálcio e de ferro em grãos de feijão (JOST, 2008). Nesses casos, a expressão genética do cruzamento somente será observada em $\mathrm{F}_{2}$ quando as sementes apresentarão cotilédones em geração $\mathrm{F}_{1}$. Consequentemente, a seleção deverá ser postergada para $\mathrm{F}_{3}$ (sementes com cotilédones em geração $\mathrm{F}_{2}$ ), quando segregação máxima será constatada. Sendo assim, o objetivo deste trabalho foi investigar a presença de efeito materno na expressão dos teores de metionina e de cisteína, em grãos de feijão, e definir a geração em que a seleção deverá ser iniciada.

Os cruzamentos controlados foram realizados entre genitores contrastantes para o teor de metionina das cultivares 'BRS Valente' $(0,79 \mathrm{~g}$ por $16 \mathrm{~g}$ de $\mathrm{N}$ da MS) x 'IAPAR 44' (0,97g por $16 \mathrm{~g}$ de $\mathrm{N}$ da MS) e para o teor de cisteína - 'TPS Nobre' (0,95g por $16 \mathrm{~g}$ de N da MS) x ‘Minuano’ (1,43g por $16 \mathrm{~g}$ de $\mathrm{N}$ da MS). As gerações $F_{1}, F_{1}$ recíproco, $F_{2}$ e $F_{2}$ recíproco foram obtidas para cada combinação híbrida, em casa-devegetação da Universidade Federal de Santa Maria (UFSM), em 2006. Os cruzamentos foram realizados por meio de emasculação do botão floral, empregando-se o método de entrelaçamento (PETERNELLI \& BORÉM, 1999).
A semeadura foi realizada em vasos plásticos com capacidade para cinco litros, sendo cultivadas duas plantas em cada vaso. Uma mistura de solo + casca de arroz carbonizada + substrato comercial Plantimax ${ }^{\circledR}$ foi empregada na proporção volumétrica de 2:1:1. O solo utilizado foi o Argissolo BrunoAcinzentado alítico típico, com a seguinte composição química: $\mathrm{pH}(\mathrm{H} 20)$ : 5,5; matéria orgânica: 2,2\%; fósforo: 6,8mg dm${ }^{-3}$; potássio: $68 \mathrm{mg} \mathrm{dm}^{-3}$; cálcio: $5,5 \mathrm{cmol}_{\mathrm{c}} \mathrm{dm}^{-3}$; magnésio: $2,7 \mathrm{cmol}_{c} \mathrm{dm}^{-3}$. A correção da fertilidade do solo e a aplicação de nitrogênio em cobertura foram efetuadas com base na análise química do solo. Irrigações diárias foram realizadas para suprir a demanda hídrica das plantas, e o controle de pragas e de moléstias foi realizado com a aplicação de produtos químicos, sempre que necessário, a fim de garantir a sanidade das plantas e a integridade dos botões florais.

Na maturação, foi realizada a colheita, e os grãos obtidos foram secados em estufa $\left(65\right.$ a $\left.70^{\circ} \mathrm{C}\right)$ até umidade média de 13\%. Amostras dos grãos de cada geração foram moídas em micromoinho, até a obtenção de partículas inferiores a 1mm. As determinações dos teores de metionina e de cisteína foram realizadas no Laboratório de Análises Micotoxicológicas (LAMIC), da UFSM, utilizando cromatografia líquida de alta performance (HPLC-UV), de acordo com a metodologia descrita em RIBEIRO et al. (2007). Os teores de aminoácidos foram transformados para gramas por $16 \mathrm{~g}$ $\mathrm{N}$ de amostra seca. Para isso, o teor de proteína bruta (PB, g por $100 \mathrm{~g}$ de matéria seca) da amostra foi

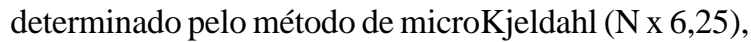
com o uso da metodologia descrita pela ASSOCIATION OF OFFICIALAGRICULTURALCHEMISTS (1995). Os teores de aminoácidos e de proteína bruta foram quantificados em duplicata.

O delineamento experimental inteiramente casualizado foi utilizado, com duas repetições para os genitores $\left(\mathrm{P}_{1}\right.$ e $\left.\mathrm{P}_{2}\right)$ e para as gerações $\mathrm{F}_{1}$ e $\mathrm{F}_{1}$ recíproco e quatro repetições para as gerações $F_{2}$ e $F_{2}$ recíproco. Para testar a hipótese de efeito materno, efetuou-se a comparação entre as médias pelo teste $t$ a $5 \%$ de significância para duas amostras independentes. Assim, foram testados os contrastes $\mathrm{P}_{1}$ versus $\mathrm{P}_{2}, \mathrm{P}_{1}$ versus $\mathrm{F}_{1}, \mathrm{P}_{2}$ versus $\mathrm{F}_{1}$ recíproco, $\mathrm{F}_{1}$ versus $\mathrm{F}_{1}$ recíproco e $\mathrm{F}_{2}$ versus $\mathrm{F}_{2}$ recíproco. As análises estatísticas foram realizadas com o auxílio do programa GENES (CRUZ, 2006).

O teor de metionina variou de $0,79 \mathrm{~g}$ por $16 \mathrm{~g}$ de $\mathrm{N}$ da MS ('BRS Valente') a 1,09g por $16 \mathrm{~g}$ de $\mathrm{N}$ da MS (geração F2) (Figura 1). Valores similares foram obtidos em cultivares americanas de feijão (ABD EL-SAMEI \& LÁSZTITY, 1984) e em feijão do tipo mulatinho, macassar e azuki cultivados no Nordeste do Brasil 


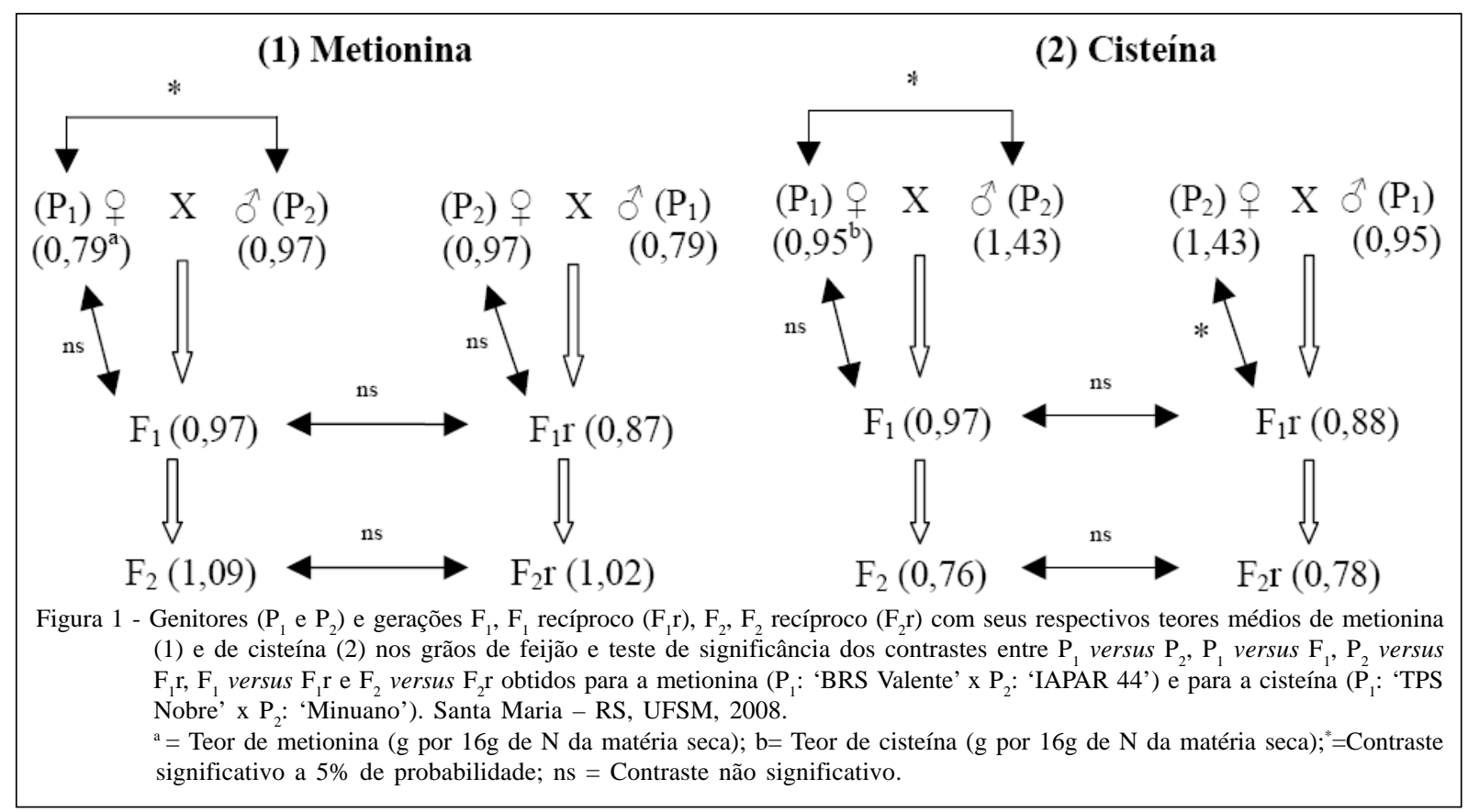

(MARQUES \& BORA, 2000). Entretanto, teores superiores foram verificados em cultivares de feijão comum disponibilizadas para o cultivo no Brasil há vários anos (ANTUNES et al., 1995).

A utilização de parentais contrastantes para o teor de metionina possibilitou a obtenção de plantas $\mathrm{F}_{2}$ com alto teor de metionina nos grãos e a observação de que a ação gênica aditiva predomina na manifestação desse caráter em feijão (KELLY \& BLISS, 1975). Entretanto, como o feijão é uma planta autógama, se espera que a heterose seja reduzida pela metade em cada geração de autofecundação e, por isso, a geração $\mathrm{F}_{3}$ poderá apresentar média inferior à geração $\mathrm{F}_{2}$, devido ao aumento da homozigose. Assim, a avaliação em gerações avançadas se faz necessária para se investigar como será a segregação para esse caráter nas populações obtidas a partir do cruzamento entre 'BRS Valente'x 'IAPAR 44'.

O teor de cisteína variou de $0,76 \mathrm{~g}$ por $16 \mathrm{~g}$ de $\mathrm{N}$ da $\mathrm{MS}$ (geração $\mathrm{F}_{2}$ ) a 1,43g por $16 \mathrm{~g}$ de $\mathrm{N}$ da $\mathrm{MS}$ ('Minuano'). Valores muito próximos foram observados em cultivares de feijão, em cultivo nos Estados Unidos (ABD EL-SAMEI \& LÁSZTITY, 1984) e no Brasil (ANTUNES et al., 1995; RIBEIRO et al., 2007). No cruzamento ‘TPS Nobre' $x$ 'Minuano', não foi possível obter gerações precoces com alto teor de cisteína nos grãos, e segregação transgressiva foi observada.

No cruzamento 'BRS Valente' $x$ 'IAPAR 44', o contraste $P_{1}$ versus $P_{2}$ foi significativo, ou seja, o teste $t$ discriminou diferenças genéticas entre os genitores para o teor de metionina (Figura 1). Os contrastes $P_{1}$ versus $F_{1}$ e $P_{2}$ versus $F_{1}$ recíproco não foram significativos, e as médias das gerações $F_{1}$ e $F_{1}$ recíproco foram similares ao genitor feminino utilizado nos cruzamentos controlados. As gerações $F_{1}$ e $F_{1}$ recíproco não diferiram significativamente, demonstrando que o fenótipo do descendente não será dependente do genótipo feminino, ou seja, não ocorre efeito materno significativo na expressão do teor de metionina em grãos de feijão. Assim, as sementes das gerações $F_{1}$ e $F_{1}$ recíproco representaram o produto da fecundação e, nesse caso, o embrião (cotilédones e eixo embrionário) caracteriza a geração $\mathrm{F}_{1}$. $O$ contraste $\mathrm{F}_{2}$ versus $\mathrm{F}_{2}$ recíproco não foi significativo, ou seja, os fenótipos dessas sementes são semelhantes. Desse modo, as sementes $F_{2}$ obtidas apresentaram embrião em geração $F_{2} e$, por isso, a seleção para maior teor de metionina deverá ser iniciada nessa geração, que apresentará grande variabilidade genética.

Para o teor de cisteína, foi obtido contraste significativo entre os genitores 'TPS Nobre' $\mathrm{x}$ 'Minuano', indicando variabilidade genética (Figura 1). Os contrastes $F_{1}$ versus $F_{1}$ recíproco e $F_{2}$ versus $F_{2}$ recíproco não foram significativos, ou seja, não ocorre efeito materno significativo na expressão do teor de cisteína em grãos de feijão. Entretanto, ocorre efeito materno para o teor de proteína (LELEJI et al., 1972), o tempo de cozimento (RIBEIRO et al., 2006) e os teores de cálcio e de ferro em grãos de feijão (JOST, 2008). Nesses casos, tegumento e cotilédones são tecidos 
que estarão presentes em gerações diferentes (RAMALHO et al., 2000), e a seleção deverá ser iniciada em geração $\mathrm{F}_{3}$ (embrião em geração $\mathrm{F}_{2}$ ). Assim, há inequívoca relevância na investigação da ocorrência de efeito materno para os caracteres que conferem qualidade nutricional e tecnológica ao feijão, pois terá implicações diretas na seleção e na condução das populações segregantes em programas de melhoramento.

Considerando que não ocorre efeito materno na expressão dos teores de metionina e de cisteína em grãos de feijão, as sementes $\mathrm{F}_{1}$ apresentaram embrião em geração $F_{1}$, indicando que esses caracteres são dependentes dos cotilédones. Assim, recomendase ao programa de melhoramento que a seleção seja iniciada em sementes $F_{2}$ (embrião em geração $F_{2}$ ), quando segregação máxima será observada. Além disso, como grande parte da população brasileira tem acesso limitado às proteínas de origem animal, a identificação de plantas com melhor qualidade de proteína é extremamente oportuna para a manutenção do estado de saúde e para a prevenção de várias doenças. Nesse sentido, a seleção de germoplasma de feijão com teores adequados de aminoácidos sulfurados representará melhor qualidade da proteína, sem alterar o sabor do tradicional arroz com feijão e sem custos adicionais para o preparo da refeição. Assim, a seleção de plantas $\mathrm{F}_{2}$, obtidas a partir do cruzamento entre 'BRS Valente' $\mathrm{x}$ 'IAPAR 44' poderá ser efetiva para o desenvolvimento de linhagens de feijão com alto teor de metionina. Além disso, um alimento mais nutritivo poderá ser incorporado aos cardápios brasileiros. Com relação à cisteína, será preciso testar outras combinações híbridas para a obtenção de plantas com alto teor desse aminoácido nos grãos.

\section{AGRADECIMENTOS}

Ao Conselho Nacional de Desenvolvimento Científico e Tecnológico (CNPq), pelo aporte financeiro e pelas bolsas concedidas. À Coordenação de Aperfeiçoamento de Pessoal de Nível Superior (CAPES) e à Fundação de Amparo a Pesquisa do Estado do Rio Grande do Sul (FAPERGS), pelas bolsas de doutorado e de iniciação científica.

\section{REFERÊNCIAS}

ABD EL-SAMEI, M.H.; LÁSZTITY, R. Comparative study on the amino acids composition in three local Phaseolus vulgaris seeds varieties. Zeitschrift für Lebensmitteluntersuchung und - Forschung A, Heidelberg, v.178, n.1, p.24-26, 1984.

ANTUNES, P.L. et al. Valor nutricional de feijão (Phaseolus vulgaris, L.), cultivares 'Rico 23', 'Carioca', 'Piratã-1' e
'Rosinha-G2'. Revista Brasileira de Agrociência, Pelotas, v.1, n.1, p.12-18, 1995.

ASSOCIATION OF OFFICIAL AGRICULTURAL CHEMISTS. Official methods of analysis. 16.ed. Washington, DC, 1995. 2000p.

CRUZ, C.D. Programa Genes: biometria. Viçosa: UFV, 2006. 382p.

FAO. Junta de Conselho de Especialistas FAO/WHO/ONU. Necessidades de energia e proteína. São Paulo: Roca, 1998. 225 p.

GUZMÁN-MALDONADO, S.H. et al. Protein and mineral content of a novel collection of wild and weedy common bean (Phaseolus vulgaris L). Journal of the Science of Food and Agriculture, London, v.80, n.13, p.1874-1881, 2000.

JOST, E. Genética dos teores de cálcio e de ferro em grãos de feijão comum. 2008. 42f. Dissertação (Mestrado em Agronomia) - Programa de Pós-graduação em Agronomia, Universidade Federal de Santa Maria.

KELLY, J.D.; BLISS, F.A. Heritability estimates of percentage seed protein and available methionine and correlations with yield in dry beans. Crop Science, Madison, v.15, n.6, p.753757, 1975.

LELEJI, O.I. et al. Inheritance of crude protein percentage and its correlation with seed yield in beans, Phaseolus vulgaris L. Crop Science, Madison, v.12, n.2, p.168-171, 1972.

MARQUES, M.F.; BORA, P.S. Composición química y análisis de aminoácidos de alubias. Ciencia y Tecnología Alimentaria, Reynosa, v.2, n.5, p.248-252, 2000.

MOLINA, S.M.G. et al. Manipulação de cereais para acúmulo de lisina nas sementes. Scientia Agrícola, Piracicaba, v.58, n.1, p.205-211, 2001. Disponível em: <http://www.scielo.br/s c i e l o.ph p ? s c ript = s ci__is s u e t o c \& pi d = 010 3 - 901620010001\&lng=pt\&nrm=iso $>$. Acesso em: 25 mar. 2009. Doi: 10.1590/S0103-90162001000100032.

PETERNELLI, L.A.; BORÉM, A. Hibridação em feijão. In: BORÉM, A. Hibridação artificial de plantas. Viçosa: UFV, 1999. p.269-294.

RAMALHO, M.A.P. et al. Genética na agropecuária. Lavras: UFLA, 2000. 472p.

RIBEIRO, S.R.R.P. et al. Maternal effect associated to cooking quality of common bean. Crop Breeding and Applied Biotecnology, Viçosa, v.6, n.4, p.304-310, 2006.

RIBEIRO, N.D. et al. Composição de aminoácidos de cultivares de feijão e aplicações para o melhoramento genético. Pesquisa Agropecuária Brasileira, Brasília, v.42, n.10, p.1393-1399, 2007. Disponível em: <http://www.scielo.br/s c i e l o . p h p ? s c r i p t $=$ s c i _ i s s u e t o c \& p i d = 0100 204X20070010\&lng=pt\&nrm=iso>. Acesso em: 25 mar. 2009. Doi: 10.1590/S0100-204X2007001000004. 